\title{
Protective effects of bisoprolol against cadmium-induced myocardial toxicity through inhibition of oxidative stress and NF-kB signalling in rats
}

\author{
Jinhua Liu ${ }^{1}$, Ying $\mathrm{Xie}^{2}$, Zhujun $\mathrm{Han}^{3}$, Hailong Wang ${ }^{3}$, Wenhu $\mathrm{Xu}^{3 凶}$ \\ ${ }^{1}$ Department of Cardiology, Central Hospital of Wuhan, Wuhan, Hubei, 430000, China \\ ${ }^{2}$ Department of Infectious Diseases, Yanbian University Hospital, Yanji, Jilin, 133000, China \\ ${ }^{3}$ Department of Cardiology, Yanbian University Hospital, Yanji, Jilin, 133000, China \\ xuwenhu@yahoo.com
}

Received: March 27, $2021 \quad$ Accepted: September 30, 2021

\begin{abstract}
Introduction: The aim of the study was to investigate the mitigative effects of bisoprolol (BIS) in cadmium-induced myocardial toxicity on oxidative stress and its inhibitive effect on nuclear factor kappa-light-chain-enhancer of activated B cells (NF-kB) signalling in rats. Material and Methods: Male albino Wistar rats were assigned to control, Cd, BIS 2 (2 mg/kg b.w.) and BIS 8 ( $8 \mathrm{mg} / \mathrm{kg}$ b.w.) groups with nine rats in each. Over four weeks, the control group was administered $1 \%$ gum acacia, all other groups received $3 \mathrm{mg} / \mathrm{kg}$ b.w. $\mathrm{CdCl}_{2}$ dissolved in distilled water, and the $\mathrm{BIS}$ groups were additionally given bisoprolol in gum acacia. Blood samples were collected for biochemical estimations. Blood pressure and serum biomarker (lactate dehydrogenase, aspirate transaminase, alanine transferase and creatine kinase-MB, enzyme (superoxide dismutase, lipid hydroxy peroxidase, catalase and malondialdehyde), and tumour necrosis factor alpha (TNF- $\alpha$ ) concentrations were measured. Western blot analysis was conducted for NF- $\mathrm{kB}$ and glutathione S-transferase (GST). After sacrificing the rats, cardiac tissue samples were examined histopathologically. Results: Our findings pointed to a significant decrease $(\mathrm{P}<0.05)$ in the studied serum biomarkers and levels of the relevant enzymes in the BIS 8 group compared to the Cd group. A significant decrease $(\mathrm{P}<0.05)$ in NF-kB p65 expression and TNF- $\alpha$ levels was noted in the BIS 8 group relative to the BIS 2 and Cd groups, indicating a reduction at a higher dose. In microscopy, histopathological changes in the cardiac muscles of the BIS 8 group were evident compared to those of the Cd group. Conclusion: BIS seemed to have protective effects against cardiac injury induced by cadmium and could be considered a novel therapeutic drug and prognostic biomarker in the pathology of the many cardiovascular diseases caused by heavy metal intake.
\end{abstract}

Keywords: cadmium, bisoprolol, catalase, myocardial toxicity.

\section{Introduction}

Cadmium is a toxic heavy metal generally found in the smoke, diet, and polluted water of industrialised societies. It is a carcinogen and causes intoxication leading to dysfunction and inducing oxidative stress, metabolic changes, and dyslipidaemia (14, 15, 22). Long-term intake of or exposure to $\mathrm{Cd}$ creates the condition for the metal to accumulate in the body causing various cardiovascular diseases (CVDs) such as atherosclerosis, hypertension, myocardial infarction, and stroke (17). Although there are several mechanisms mediated by $\mathrm{Cd}$ causing cardiovascular toxicity, their exact natures have not yet been explored. One of these mechanisms is oxidative stress, caused by uncontrollable and excessive production of oxidants such as reactive oxygen and nitrogen species (ROS, RNS). This disrupts several physiological functions of the cells because it damages DNA, leading to organ intoxication, multiple organ failure, cancer and various other chronic diseases (17). Ions of $\mathrm{Cd}$ have a high affinity for biological membranes, which cause lipid peroxidation due to the release of malondialdehyde (MDA), leading to abnormal metabolic reactions (2).

Cadmium-induced oxidative stress increases biomarker levels, mainly those of creatine phosphokinase and lactate dehydrogenase (LDH). These two biomarkers are diagnostic indicators of 
cardiomyopathies involving endothelial and myocardial cell injuries. Reduced levels of antioxidant enzymes such as catalase (CAT) and glutathione peroxidase $(2,23)$ correlate to excess production of ROS induced by oxidative stress. The acceleration of endothelial damage in myocardial tissues due to oxidative stress involves ROS activating the nuclear factor kappa-light-chainenhancer of activated $\mathrm{B}$ cell $(\mathrm{NF}-\mathrm{KB})$ transcription factor and excess production of cytokines, thus exacerbating ailments such as myocardial infarction and angina pectoris $(8,13,16)$.

The competitive $\beta$-blocker bisoprolol (BIS) has antioxidant property and this is exploited to treat mild to moderate hypertension, myocardial infarction, and congestive heart failure (8). It has been shown in several studies that BIS offers cardioprotective effects against apoptosis, autophagy, and oxidative stress through modulation of immune and inflammatory mediators $(6,9,18)$. Additionally, BIS demonstrated a protective effect against myocardial ischaemia/reperfusion injury by reducing the size of an infarct. Bisoprolol was found to decrease serum levels of creatinine kinase and lactate dehydrogenase, lower the apoptotic index, and suppress tumour necrosis factor alpha (TNF- $\alpha$ ) and interleukin 6 mediators, thus downregulating the caspase 3 and caspase 12 signalling pathways (25). The direct involvement of TNF- $\alpha$ in NF-KB activation is significant in inflammatory progression $(3,5)$. Hence, reductions in myocardial injury can be achieved by inhibiting the activation of NF-kB through the TNF- $\alpha$ mediated pathway (5).

Given the diversity of mechanisms involved in cadmium-induced cardiac injury, the beneficial protective effects of BIS prompted us to further explore its role in $\mathrm{Cd}$ cardiotoxicity. There were no scientific studies or reports available on this subject at the time of writing. Therefore, our study aimed to investigate the cardioprotective effects of BIS in cadmium-induced cardiotoxicity and investigate whether its protective mechanism involves mitigation of oxidative stress via the activation of NF-KB signalling in the rat model.

\section{Material and Methods}

Chemicals. Bisoprolol and cadmium (Cd) chloride were obtained in powder form from Sigma Aldrich, St. Louis, MO, USA. The ELISA for TNF- $\alpha$ and immunostaining PCR kits were bought from Thermo Fisher Scientific (Waltham, MA, USA). The LDH, alanine transferase (ALT), and aspirate transaminase (AST) enzymatic kits were supplied by Sigma Aldrich. For Western blotting, the primary and secondary antibodies were procured from QED Bioscience, CA, USA. Only analytical grade chemicals and reagents were used for the experiments.

Animals and experimental design. The study was conducted on 36 adult male rats (Wistar albino; 200-250 g), which were obtained from the Animal Research Centre,
Beijing, China. The animals were divided into four groups of 9 and housed with standard chow and water for acclimation for two weeks. A suspension of BIS was prepared using $1 \%$ gum acacia, and the cadmium chloride was dissolved in distilled water. The control group were administered a suspension containing $1 \%$ gum acacia, the $\mathrm{Cd}$ group received $\mathrm{CdCl}_{2}(3 \mathrm{mg} / \mathrm{kg}$ b.w. per day), the BIS 2 group were given BIS ( $2 \mathrm{mg} / \mathrm{kg}$ b.w. per day) with $\mathrm{CdCl}_{2}$ (3 $\mathrm{mg} / \mathrm{kg}$ b.w. per day), and the BIS 8 group ingested BIS ( $8 \mathrm{mg} / \mathrm{kg}$ b.w. per day) with $\mathrm{CdCl}_{2}$ ( $3 \mathrm{mg} / \mathrm{kg}$ b.w. per day). Administration was by gavage and was over a four-week duration for all groups.

Collection of samples and storage. Blood samples were collected from rats at the end of the study under light ether anaesthesia through the orbital plexus. The samples were centrifuged at 3,000 rpm for serum separation for $15 \mathrm{~min}$, and the supernatant thus obtained was stored at $-20^{\circ} \mathrm{C}$ for biochemical estimation. The animals were sacrificed by decapitation. Heart tissues were excised from each rat, washed with saline and weighed. Small sections of heart tissue were placed in a $10 \%$ solution of formalin in order for histopathological and immunological studies to be carried out. The remaining heart specimens were stored at $-80^{\circ} \mathrm{C}$ for further biochemical evaluation including Western blot analysis.

Measurement of blood pressure. Blood pressure was measured and recorded for $15 \mathrm{~min}$ at $37^{\circ} \mathrm{C}$ using an LE5002 non-invasive blood pressure apparatus (Panlab, Harvard Apparatus, Barcelona, Spain). The data were obtained through the acquisition system connected to the computer screen. The tail cuff was inflated until pulsations ceased. The cuff was then deflated, and pulsations were detectable again. The experiments were repeated five times.

Estimation of serum cardiac enzyme biomarkers. The serum biomarkers of the heart (creatine kinase-MB (CK-MB) and LDH) were determined following the manufacturer's protocols provided with commercially available kits (BioSystems, Barcelona, Spain), where the amount of serum enzyme biomarkers was determined according to their absorbance and expressed in U/L.

Estimation of serum AST and ALT. The colorimetric method was used to measure AST and ALT levels using standard commercially available kits (Biobase Meihua Trading Co., Ltd., Jinan, China). The levels of AST and ALT were also expressed as U/L.

Estimation of MDA, CAT, lipid hydroxyperoxide (LPO), and superoxide dismutase (SOD). The cardiac tissues were instantly collected after euthanasia and homogenised $(10 \% \mathrm{w} / \mathrm{v})$ employing a homogeniser in ice-cold phosphate buffer $(0.2 \mathrm{M}, \mathrm{pH}$ 6.8) and centrifuged at $4^{\circ} \mathrm{C}$ and $10,000 \mathrm{rpm}$ for $25 \mathrm{~min}$. The enzyme levels of SOD, MDA, CAT and LPO were estimated according to the method used in previous studies $(7,20)$ employing commercially available kits (Kehua Bioengineering, Shanghai, China). The activity of MDA, CAT, SOD and LPO was expressed as nmol/g 
tissue, $\mathrm{mmol} / \mathrm{min} / \mathrm{g}$ tissue, $\mathrm{U} \mathrm{SOD} / \mathrm{g}$ tissue and $\mathrm{mmol}$ hydroperoxide/g, respectively.

Estimation of TNF- $\alpha$. The level of TNF- $\alpha$ in serum was determined by the standard ELISA method following the instructions given in the manufacturer's protocol (Bioassay Technology Lab, Shanghai, China). TNF- $\alpha$ levels were denoted in the unit $\mathrm{ng} / \mathrm{g}$ tissue.

Western blot analysis. Isolation of proteins was carried out in accordance with the method described by Ansari et al. (1) in ice-cold phosphate buffer solution, mincing and homogenising the mixture after adding protease inhibitor and lysis buffer. Total proteins were determined as per the description given by Lowry et al. (13) by incubating cell lysates for $1 \mathrm{~h}$ with vortex mixing and centrifuging for $15 \mathrm{~min}$ at $4^{\circ} \mathrm{C}$ and $12,000 \mathrm{rpm}$. The Western blot analysis was conducted employing the method described by Ansari et al. (1). Samples of $30 \mathrm{mg}$ mass of the proteins from each group were separated using $10 \%$ SDS-PAGE gel and deposited onto nitrocellulose membranes. The protein blots thus separated were charged with primary antibodies for NF-KB p65 and GST, while secondary antibodies were conjugated with peroxidase and incubated overnight at $25^{\circ} \mathrm{C}$. The chemiluminescence method was used to visualise bands and their intensities were compared to $\beta$-actin bands using ImageJ (22) and Prism 8 (GraphPad, San Diego, CA, USA) programs.

Histopathological examination. The heart specimens were placed in 10\% formalin solution and fixed in paraffin for $1 \mathrm{~h}$. These specimens were sectioned and stained with eosin and haematoxylin, and examined to assess the histological changes using a light microscope (Olympus Corporation, Tokyo, Japan). The alterations noted in the structure were considered in order to evaluate cardiac tissue injury. Pathological lesions were graded semi-quantitatively based on the extent and severity, with 0 indicating normal, 1 mild, 2 moderate and 3 severe histological changes.

Statistical analysis. The values were expressed as mean \pm SEM. The data were analysed using Student's $t$-test for comparing two groups. One-way ANOVA was used for comparing more than two groups followed by Tukey's test. Prism 8 (GraphPad) was used to perform statistical analysis. Values of $\mathrm{P}<0.05$ were considered significant.

\section{Results}

Effect of Bisoprolol on mean arterial pressure (MAP) and cardiac enzyme biomarkers. The level of MAP was recorded as $82.33 \pm 1.453 \mathrm{~mm} \mathrm{Hg}$ in the control group, whereas this parameter increased significantly in the Cd group to $157.7 \pm 3.844 \mathrm{~mm} / \mathrm{Hg}$ and the BIS 2 group to $123.3 \pm 6.009 \mathrm{~mm} \mathrm{Hg}(\mathrm{P}<0.001)$. However, no significant change was seen in MAP in the BIS 8 group at $84 \pm 3.055 \mathrm{~mm} \mathrm{Hg}(\mathrm{P}>0.05$; Fig. 1a).

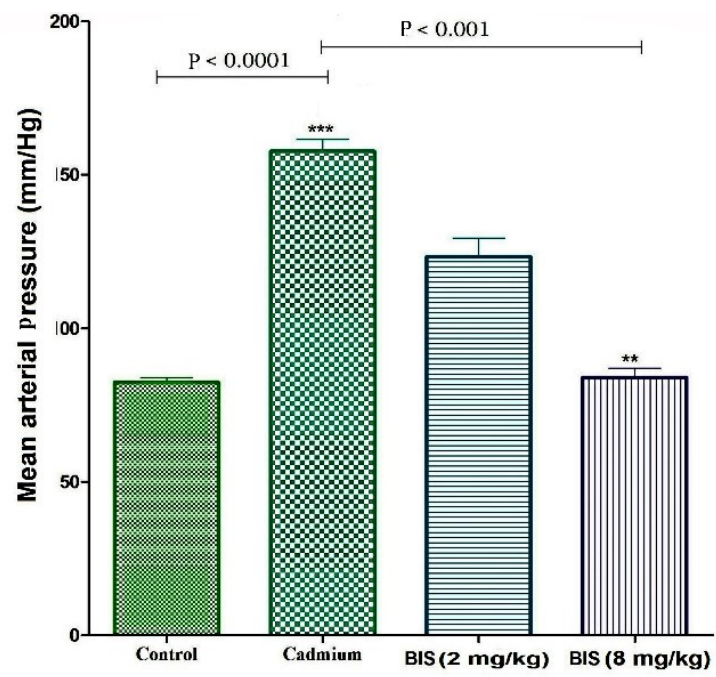

Fig. 1a. Mean arterial pressure (MAP) in rats treated with cadmium and bisoprolol (BIS) (2 and $8 \mathrm{mg} / \mathrm{kg} /$ day). Values are expressed as mean $\pm \operatorname{SEM}(\mathrm{n}=9)$. ${ }^{* * *} \mathrm{P}<0.0001$ for significant difference versus the control group; ${ }^{* *} \mathrm{P}<0.001$ for significant difference versus the Cd-treated group (using one-way ANOVA, including Dunnett's test)

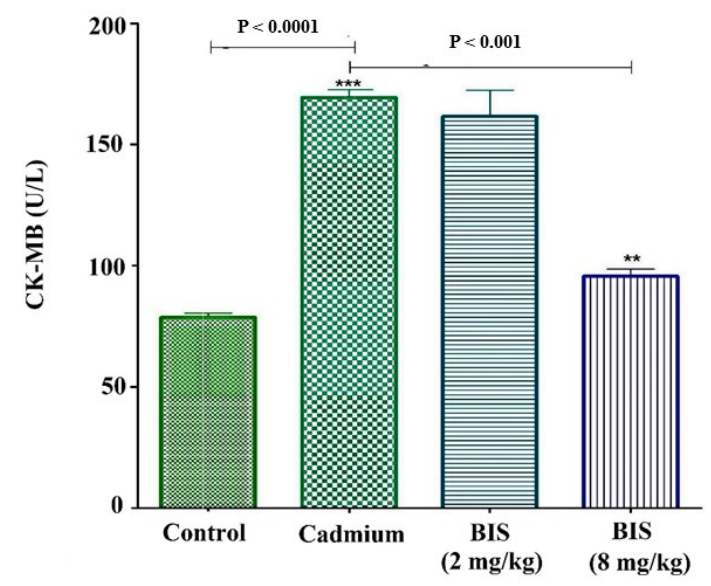

Fig. 1b. Serum creatine kinase-MB (CK-MB) levels in rats treated with cadmium and bisoprolol (BIS) (2 and $8 \mathrm{mg} / \mathrm{kg} /$ day). Values are expressed as mean \pm SEM $(\mathrm{n}=9) .{ }^{* * *} \mathrm{P}<0.0001$ for significant difference versus the control group; ${ }^{* *} \mathrm{P}<0.001$ for significant difference versus the Cd-treated group (using one-way ANOVA, including Dunnett's test)

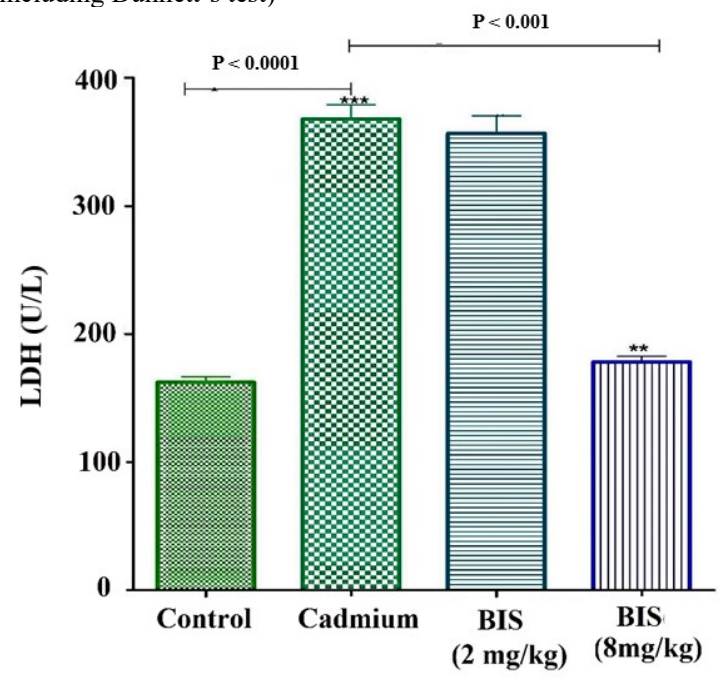

Fig. 1c. Serum lactic acid dehydrogenase (LDH) levels in rats treated with cadmium and bisoprolol (BIS) ( 2 and $8 \mathrm{mg} / \mathrm{kg} /$ day). Values are expressed as mean \pm SEM $(\mathrm{n}=9)$. $* * * \mathrm{P}<0.0001$ for significant difference versus the control group; ** $\mathrm{P}<0.001$ for significant difference versus the Cd-treated group (using one-way ANOVA, including Dunnett's test) 


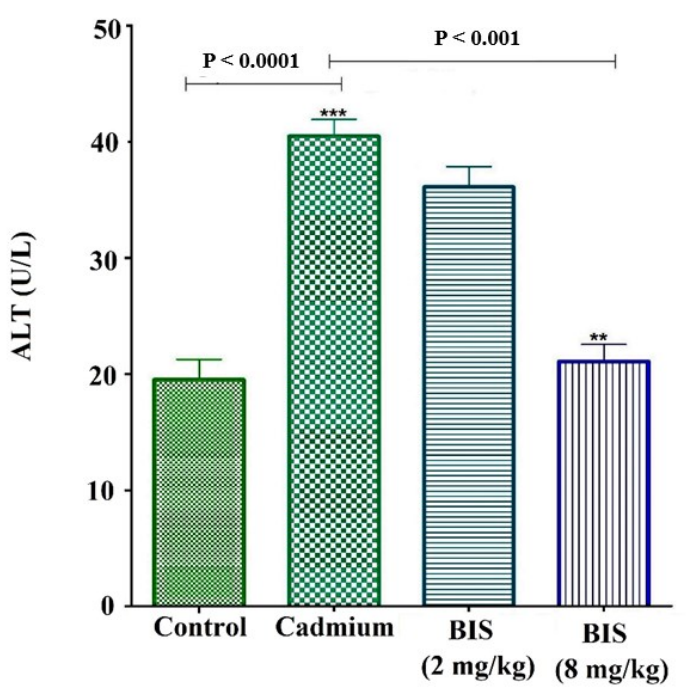

Fig. 1d. Serum alanine aminotransferase (ALT) levels in rats treated with cadmium and bisoprolol (BIS) (2 and $8 \mathrm{mg} / \mathrm{kg} / \mathrm{day})$. Values are expressed as mean \pm SEM $(\mathrm{n}=9)$. $* * * \mathrm{P}<0.0001$ for significant difference versus the control group; $* * \mathrm{P}<0.001$ for significant difference versus the Cd-treated group (using one-way ANOVA, including Dunnett's test)

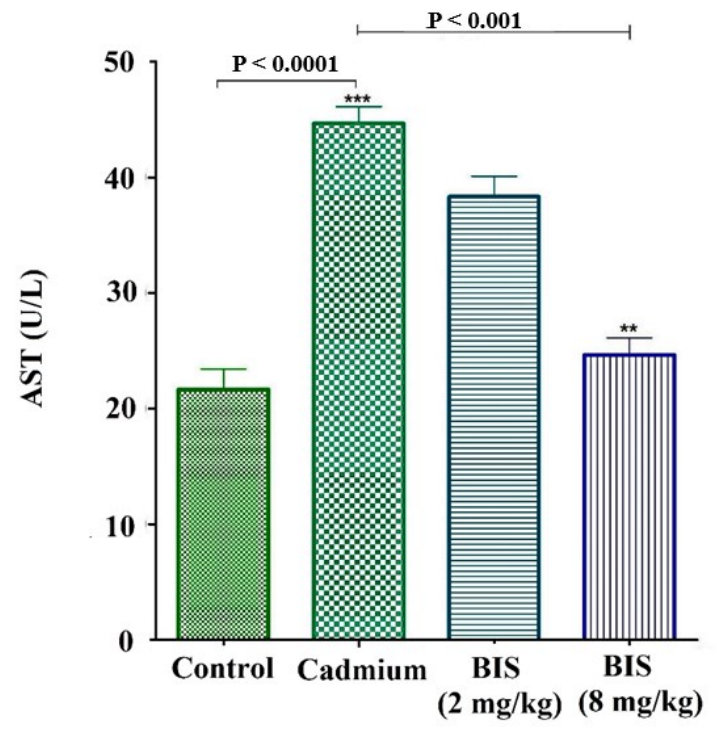

Fig. 1e. Serum aspartate aminotransferase (AST) levels in rats treated with cadmium and bisoprolol (BIS) (2 and $8 \mathrm{mg} / \mathrm{kg} / \mathrm{day})$. Values are expressed as mean \pm SEM $(\mathrm{n}=9) .{ }^{* * *} \mathrm{P}<0.0001$ for significant difference versus the control group; $* * \mathrm{P}<0.001$ for significant difference versus the Cd-treated group (using one-way ANOVA, including Dunnett's test)

The level of CK-MB was significantly higher at $167.7 \pm 1.764 \mathrm{U} / \mathrm{L}$ in the $\mathrm{Cd}$ group when compared to $78.67 \pm 1.856 \mathrm{U} / \mathrm{L}$ in the control group and $98.33 \pm 0.8819 \mathrm{U} / \mathrm{L}$ in the BIS 8 group $(\mathrm{P}<0.05)$. The latter value indicated an approximately normal level of CK-MB in the BIS 8 group comparable to that of the control group but also a level significantly lower than that of the BIS 2 group (Fig.1b). A similar trend was noticed in the Cd-intoxicated rats in LDH (Fig. 1c), ALT (Fig. 1d) and AST (Fig. 1e) levels after treatment with BIS at both 2 and $8 \mathrm{mg} / \mathrm{kg}$ b.w.

Effect of bisoprolol on SOD, MDA, CAT and LPO in cadmium-induced cardiotoxicity. Cardiac tissue analysis was used to determine enzyme levels of
MDA, CAT, SOD and LPO. The MDA level increased significantly in Cd-treated rats $(99 \pm 1.528 \mathrm{mmol} / \mathrm{g}$ tissue) compared with the control group $(27.33 \pm 1.202 \mathrm{mmol} / \mathrm{g}$ tissue; $\mathrm{P}<0.001)$. However, co-administration with $\mathrm{Cd}$ of BIS at $8 \mathrm{mg} / \mathrm{kg}(42.33 \pm 2.603 \mathrm{mmol} / \mathrm{g}$ tissue $)$ caused a significantly smaller increase in MDA than co-administration with the smaller $2 \mathrm{mg} / \mathrm{kg}$ dose of BIS $(81 \pm 2.082 \mathrm{mmol} / \mathrm{g}$ tissue; $\mathrm{P}<0.001)$ and in fact left the MDA level close to normal in the higher-concentration BIS recipients (Fig. 2). The SOD level was significantly higher $(36.76 \pm 1.89 \mathrm{SOD} / \mathrm{g}$; $\mathrm{P}<0.001)$ in the BIS 8 group when compared to that of the Cd group $(19.81 \pm 0.67 \mathrm{SOD} / \mathrm{g})$. The CAT level in Cd-treated rats was $2.897 \pm 0.34 \mathrm{mmol} / \mathrm{min} / \mathrm{g}$ and found to be increased significantly $(\mathrm{P}=0.0014)$ after treatment with $8 \mathrm{mg} / \mathrm{kg}$ BIS group $(3.167 \pm 0.289 \mathrm{mmol} / \mathrm{min} / \mathrm{g})$ thus restoring to the normal of the control group $(3.167 \pm 0.289 \mathrm{mmol} / \mathrm{min} / \mathrm{g})$. The LPO level was comparable to normal in the BIS 8 group $(823.8 \pm 18.13 \mathrm{mmol}$ hydrogen peroxide/g against $894.3 \pm 14.61 \mathrm{mmol}$ hydroperoxide/g in the control group) and significantly lower than that of the Cd group $(1639 \pm 56.23 \mathrm{mmol}$ hydrogen peroxide $/ \mathrm{g}$; $\mathrm{P}<0.001)$. This indicates that only after BIS treatment at the higher dose $(8 \mathrm{mg} / \mathrm{kg})$ and not after treatment at the lower dose $(2 \mathrm{mg} / \mathrm{kg})$ was this enzyme level unchanged from its norm in $\mathrm{Cd}$-induced myocardial injury (Table 1).

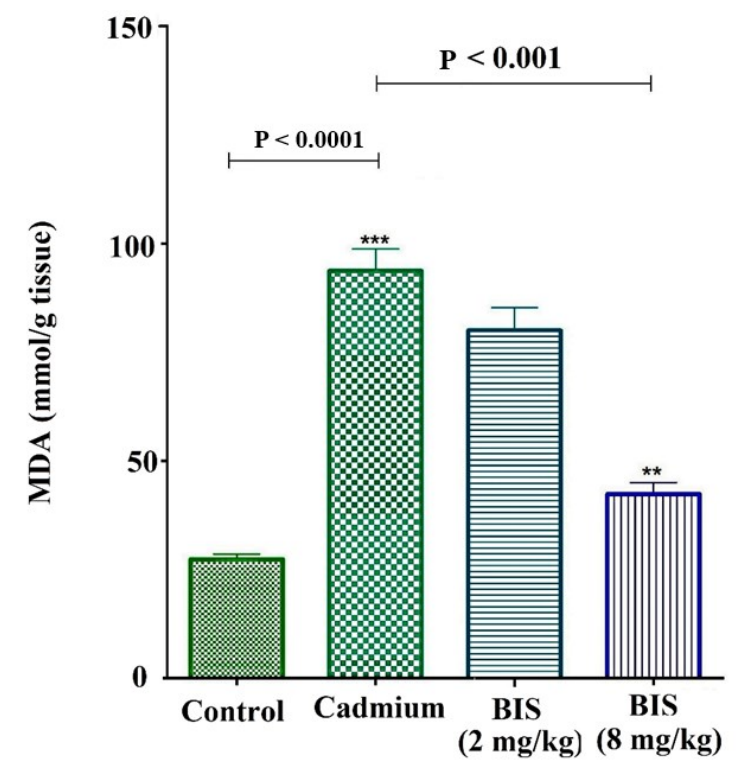

Fig. 2. Malondialdehyde (MDA) levels in cardiac tissue from rats treated with cadmium and bisoprolol (BIS) $(2$ and $8 \mathrm{mg} / \mathrm{kg} / \mathrm{day})$. Values are expressed as mean $\pm \operatorname{SEM}(\mathrm{n}=9)$. $* * * \mathrm{P}<0.0001$ for significant difference versus the control group; ** $\mathrm{P}<0.001$ for significant difference versus the Cd-treated group (using one-way ANOVA, including Dunnett's test)

Effect of bisoprolol on TNF-a cardiac tissue levels. The TNF- $\alpha$ cardiac tissue level was significantly increased in Cd treated rats $(55.23 \pm 1.445 \mathrm{ng} / \mathrm{g}$ tissue $)$ compared to the control group ( $10.83 \pm 1.13 \mathrm{ng} / \mathrm{g}$ tissue $)$. Treatment with BIS at $8 \mathrm{mg} / \mathrm{kg}$ co-administered with $\mathrm{Cd}$ resulted in a significantly smaller TNF- $\alpha$ level increase $(24.53 \pm 1.084 \mathrm{ng} / \mathrm{g}$ tissue; $\mathrm{P}<0.001)$ than treatment with $\mathrm{Cd}$ and BIS at $2 \mathrm{mg} / \mathrm{kg}(56.53 \pm 1.519 \mathrm{ng} / \mathrm{g}$ tissue) (Fig. 3). 
Table 1. Quantitative data on the cardiac tissue antioxidant enzymes in rats treated with cadmium and BIS (2 and $8 \mathrm{mg} / \mathrm{kg} / \mathrm{day})$

\begin{tabular}{llll}
\hline Parameter & Control & Cadmium & BIS (2 mg/kg) \\
\hline SOD (unit of SOD/g tissue) & $41.5 \pm 3.67$ & $19.81 \pm 0.67 * * *$ & $21.1 \pm 3.12 \#$ \\
CAT (mmol/min/g tissue) & $3.32 \pm 1.64$ & $2.897 \pm 0.34 * * *$ & $2.521 \pm 0.22 \#$ \\
LPO (nmol hydroperoxides/g tissue) & $894.3 \pm 14.61$ & $1639 \pm 56.23 * * *$ & $1556.5 \pm 45.23 \#$ \\
\hline
\end{tabular}

Values are expressed as mean \pm S.E.M. $* * * \mathrm{P}<0.0001$ for significant increase in superoxide dismutase (SOD), catalase (CAT) and lipid peroxidation (LPO) levels versus the control group; ** $\mathrm{P}<0.001$ for significant decrease in SOD, CAT and LPO levels after treatment with BIS at $8 \mathrm{mg} / \mathrm{kg} /$ day versus the Cd treated group

\section{Western blot analysis of effect of BIS on NF-kB} p65 and glutathione S-transferase (GST). Figures $4 \mathrm{a}$ and $4 \mathrm{~b}$ show the results of BIS treatments on NF-KB p65 and GST. The expression of NF-KB p65 indicated this protein's activation, implying its significant role in producing inflammatory mediators. The results demonstrated that in cadmium-treated rats, NF-кB p65 expression was notably upregulated from that in control rats. However, BIS 8 group rats exhibited significantly less phosphorylated and non-phosphorylated NF-KB p65 expression than $\mathrm{Cd}$ group animals. Furthermore, $\mathrm{Cd}-$ treated rats evinced a significant decrease in GST expression $(\mathrm{P}<0.001)$ when compared to the control group. Nevertheless, the BIS 8 group rats showed significantly higher $(\mathrm{P}<0.001)$ expression of GST compared to the $\mathrm{Cd}$ group and this expression was approximately at the normal level.

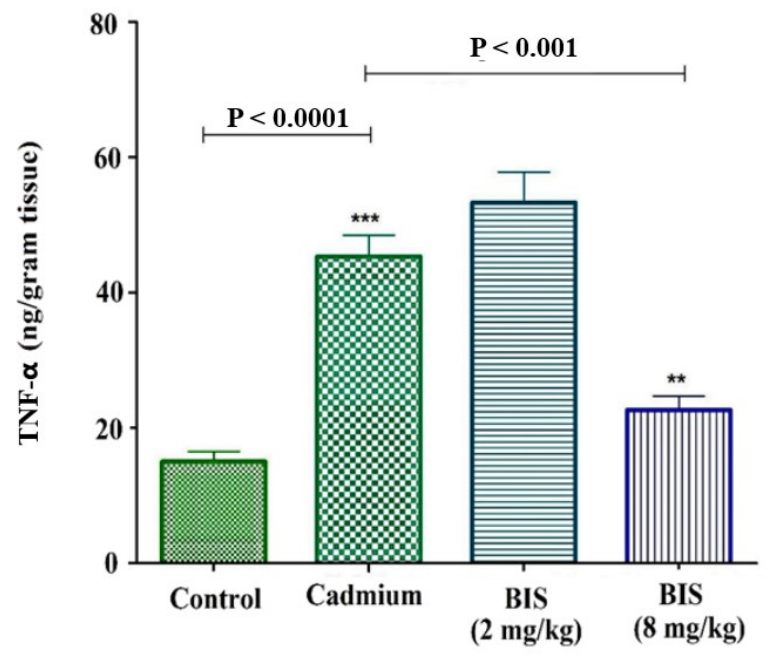

Fig. 3. Tumour necrosis factor alpha (TNF- $\alpha$ ) from cardiac tissue of rats treated with cadmium and bisoprolol (BIS) (2 and $8 \mathrm{mg} / \mathrm{kg} /$ day). Values are expressed as mean $\pm \operatorname{SEM}(\mathrm{n}=9)$. *** $\mathrm{P}<0.0001$ for significant difference versus the control group; $* * \mathrm{P}<0.001$ for significant difference versus the Cd-treated group (using one-way ANOVA, including Dunnett's test)

Western blot analysis of effect of BIS on NFкB p65 and glutathione S-transferase (GST). Figures $4 \mathrm{a}$ and $4 \mathrm{~b}$ show the results of BIS treatments on NF-KB p65 and GST. The expression of NF-kB p65 indicated this protein's activation, implying its significant role in producing inflammatory mediators. The results demonstrated that in cadmium-treated rats, NF-кB p65 expression was notably upregulated from that in control rats. However, BIS 8 group rats exhibited significantly less phosphorylated and non-phosphorylated NF-KB p65 expression than $\mathrm{Cd}$ group animals. Furthermore, Cd-treated rats evinced a significant decrease in GST expression $(\mathrm{P}<0.001)$ when compared to the control group. Nevertheless, the BIS 8 group rats showed significantly higher $(\mathrm{P}<0.001)$ expression of GST compared to the $\mathrm{Cd}$ group and this expression was approximately at the normal level.

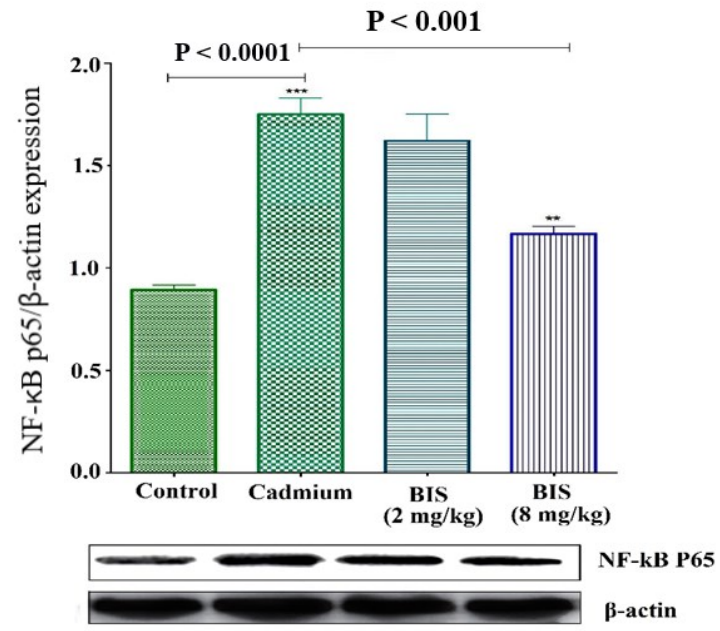

Fig. 4a. Cardiac tissue homogenate NF- $\kappa B-p 65 / \beta$-actin expression from Western blot analysis in rats treated with cadmium and bisoprolol (BIS) $(2$ and $8 \mathrm{mg} / \mathrm{kg} /$ day). Values are expressed as mean $\pm \mathrm{SEM}(\mathrm{n}=$ 9). *** $\mathrm{P}<0.0001$ for significance difference versus the control group; $* * \mathrm{P}<0.001$ for significance difference versus the Cd-treated group (using one-way ANOVA, including Dunnett's test)

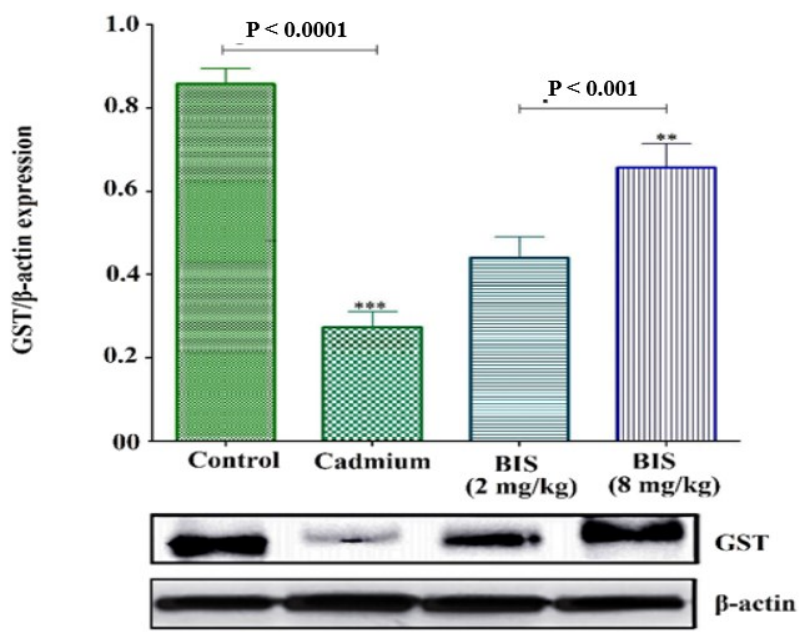

Fig. 4b. Cardiac tissue homogenate GST/ $\beta$-actin expression from Western blot analysis in rats treated with cadmium and bisoprolol (BIS) $(2$ and $8 \mathrm{mg} / \mathrm{kg} /$ day). Values are expressed as mean $\pm \mathrm{SEM}(\mathrm{n}=$ 9). ${ }^{* * *} \mathrm{P}<0.0001$ for significance difference versus the control group; ** $\mathrm{P}<0.001$ for significance difference versus the Cd-treated group (using one-way ANOVA, including Dunnett's test) 


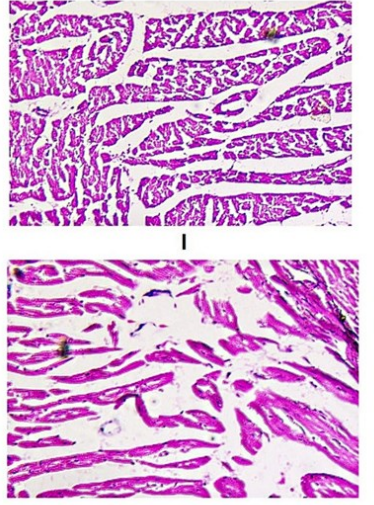

III

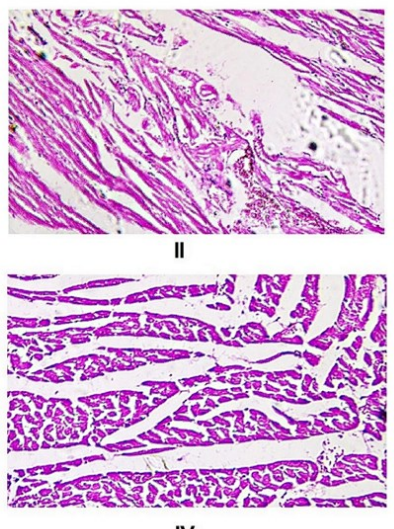

IV
Fig. 5. Effect of bisoprolol on cadmium-induced cardiotoxicity. I - the control group showing normally preserved cardiac muscle architecture; II - the cadmium-treated group showing subendocardial necrosis with no muscle striations, pyknotic nuclei and vascular congestion; III - the cadmium and $2 \mathrm{mg} / \mathrm{kg}$ BIS-treated group showing moderate improvement with congestion and no muscle striations; IV - the cadmium and $8 \mathrm{mg} / \mathrm{kg}$ BIS-treated group showing marked improvement with mild congestion

Histopathological assessment. The grades of histopathological findings were as follows: the control group was given a score of 0 and graded as normal; the Cd group was given a score of 3 and graded as severe; the BIS 2 group was given a score of 2 and graded as moderate and the BIS 8 group was given a score of 1 and graded as mild (Fig. 5).

\section{Discussion}

Cadmium $(\mathrm{Cd})$ is a lethally toxic environmental pollutant as well as a human carcinogen, intoxication with which leads to various cardiovascular diseases. The severity of the effect depends on the dose and duration of exposure to $\mathrm{Cd}$ (15). Our study is the first to investigate the protective effects of bisoprolol against cadmium cardiotoxicity involving mitigation of oxidative stress and weakening of the activation of the NF-kB signalling pathway by the drug. In the current study, a significant Cd-intoxication-induced increase was observed in MAP, cardiac enzyme biomarker and TNF- $\alpha$ levels, and NF-KB activation, with notable cellular damage, necrotic tissue, inflammation, vascular congestion, and loss of cardiac muscle striations representing histopathological changes. Our experimental findings showed that the $8 \mathrm{mg} / \mathrm{kg} /$ day dose of BIS prevented cadmium-induced oxidative stress in rats when simultaneously administered with cadmium orally for four weeks. Cadmium toxicity was severely injurious to cardiac tissue, which was manifested in an increase in the cardiac biomarkers LDH, CK-MB, and ALT. The elevation of MAP and the increases in specific and nonspecific biomarkers were in agreement with the findings of a previous study reported by Sarmiento Ortega et al. (21). The main harmful effects inflicting the cardiac injury were due to an imbalance between oxidant and antioxidant markers resulting in excessive production of ROS and RNS species and thus reducing antioxidant defence. Heavy metal damage of the plasma membrane is in the form of lipid peroxidation, resulting in increased levels of myocardial LPO (12) due to excess free radical generation and weaker antioxidant defence. Treatment with BIS restrained the MDA and LPO levels to the normal level while these were elevated in the intoxicated untreated rats, thus demonstrating the antioxidant effects of the drug. Additionally, our findings implied that BIS prevented cellular injury caused by oxidative damage because the reduced SOD and CAT activities in recipient rats were consistent with cells remaining intact.

BIS is a third-generation $\beta$-blocker having various receptor-site obstructing properties which include antioxidation, anti-apoptotic, and anti-arrhythmic effects as well as inhibition of neutrophil infiltration (25). It provides a theoretical foundation for therapeutic prevention of most CVDs, hence the depiction of BIS as a myocardial protective agent. The remarkable increase in inflammatory cytokine production, particularly of cardiac TNF- $\alpha$, was indicative of $\mathrm{Cd}$-induced cardiotoxicity. This occurred due to an increase in ROS production leading to NF-KB translocation and upregulation of TNF- $\alpha$ and mRNA expression. Likewise, excessive production of TNF- $\alpha$ stimulates pro-inflammatory cytokine release and activates NF-KB associated with inflammation (10). Our findings showed significantly weaker TNF- $\alpha$ and NF-KB signalling potentiation when the higher BIS dose was administered to cadmium-cardiointoxicated rats. It is well known that inflammatory stimuli, pollutants, and stress activate $\mathrm{NF}-\mathrm{KB}$, which is correlated to increase in ROS sensitivity $(4,11)$. Previous studies demonstrated the stimulation of apoptosis due to cadmium toxicity involving $\mathrm{NF}-\mathrm{KB}$ activation in rats (24). Our study proved that cadmium-induced oxidative stress causes NF-KB activation with an increase in GST. However, treatment with BIS effectively counteracted myocardial oxidative stress by inhibiting NF-KB signal transduction pathways and upregulating GST expression. Our observations of NF-kB and GST expression corroborated previous findings (25) suggesting the protective role of BIS in cadmium-induced cardiac toxicity in its mediating oxidative stress causing activation of NF-KB signalling together with GST expression.

The histological findings show abnormal changes in cadmium-intoxicated rat cardiac tissue, namely sub-endocardial necrosis with no vascular congestion and muscle striations. No significant differences were noticed in the histological findings between the BIS 8 group and the control group, indicating that BIS imparts an anti-oxidative effect to prevent the histological changes caused by cadmium cardiotoxicity. Based on the present study, BIS could be a useful cardioprotective drug against $\mathrm{Cd}$-induced damage and a novel biomarker for use in developing therapeutic strategies in the pathology of many cardiovascular diseases, especially those caused by heavy metal exposure. However, further studies are desirable to explore the exact protective effects of BIS involving molecular mechanisms. 
Conflict of Interests Statement: The authors declare that there is no conflict of interests regarding the publication of this article.

Financial Disclosure Statement: This study was supported by the National Natural Science Foundation of China Youth Program (no. 23_963).

Animal Rights Statement: The experiments on animals were conducted in accordance with the local Ethical Committee laws and regulations as regards care and use of experimental animals approved under number IEC/JL/YUH_34/20.

\section{References}

1. Ansari M.A., Maayah Z.H., Bakheet S.A., El-Kadi A.O., Korashy H.M.: The role of aryl hydrocarbon receptor signaling pathway in cardiotoxicity of acute lead intoxication in vivo and in vitro rat model. Toxicology 2013, 306, 40-49, doi: 10.1016/ j.tox.2013.01.024.

2. Ayala A., Muñoz M.F., Argüelles S.: Lipid peroxidation: production, metabolism, and signaling mechanisms of malondialdehyde and 4-hydroxy-2-nonenal. Oxid Med Cell Longev 2014, 2014, 360438, doi: 10.1155/2014/360438.

3. Barnes P.J., Karin M.: Nuclear factor-kappaB: a pivotal transcription factor in chronic inflammatory diseases. N Engl J Med 1997, 336, 1066-1071, doi: 10.1056/ NEJM199704103361506.

4. Bar-Shai M., Carmeli E., Ljubuncic P., Reznick A.Z.: Exercise and immobilization in aging animals: the involvement of oxidative stress and NF- $\kappa$ B activation. Free Radic Biol Med 2008, 44, 202-214, doi: 10.1016/j.freeradbiomed.2007.03.019.

5. Brasier A.R.: The NF-kappaB regulatory network. Cardiovasc Toxicol 2006, 6, 111-130, doi: 10.1385/CT:6:2:111.

6. Choi K.H., Lee G.Y., Choi J.-O., Jeon E.-S., Lee H.-Y., Lee S.E., Kim J.-J., Chae S.C., Baek S.H., Kang S.-M., Choi D.-J., Yoo B.-S., Kim K.H., Cho M.-C., Park H.-Y., Oh B.-H.: The mortality benefit of carvedilol versus bisoprolol in patients with heart failure with reduced ejection fraction. Korean J Intern Med 2019, 34, 1030-1039, doi: 10.3904/kjim.2018.009.

7. Esterbauer H., Cheeseman K.H.: Determination of aldehydic lipid peroxidation products: malonaldehyde and 4-hydroxynonenal. Methods Enzymol 1990, 186, 407-421, doi: 10.1016/00766879(90)86134-H.

8. Eweda S.M., Newairy A.S.A., Abdou H.M., Gaber A.S.: Bisphenol A-induced oxidative damage in the hepatic and cardiac tissues of rats: The modulatory role of sesame lignans. Exp Ther Med 2020, 19, 33-44, doi: 10.3892/etm.2019.8193.

9. Fröhlich H., Torres L., Täger T., Schellberg D., Corletto A., Kazmi S., Goode K., Grundtvig M., Hole T., Katus H.A., Cleland J.G.F., Atar D., Clark A.L., Agewall S., Frankenstein L.: Bisoprolol compared with carvedilol and metoprolol succinate in the treatment of patients with chronic heart failure. Clin Res Cardiol 2017, 106, 711-721, doi: 10.1007/s00392-017-1115-0.

10. Kupsco A., Schlenk D.: Oxidative stress, unfolded protein response, and apoptosis in developmental toxicity. Int Rev Cell Mol Biol 2015, 317, 1-66, doi: 10.1016/bs.ircmb.2015.02.002.
11. Kwak J-H., Jung J-K., Lee H.: Nuclear factor-kappa B inhibitors; a patent review (2006-2010). Expert Opin Ther Pat 2011, 21, 1897-1910, doi: 10.1517/13543776.2011.638285.

12. Larregle E.V., Varas S.M., Oliveros L.B., Martinez L.D., Antón R., Marchevsky E., Giménez M.S.: Lipid metabolism in liver of rat exposed to cadmium. Food Chem Toxicol 2008, 46, 1786-1792, doi: 10.1016/j.fct.2008.01.018

13. Lowry O.H., Rosebrough N.J., Farr A.L., Randall R.J.: Protein measurement with the Folin phenol reagent. J Biol Chem 1951, 193, 265-275, doi: 10.1016/S0021-9258(19)52451-6.

14. Nazam Ansari M, Bhandari U., Pillai K.K.: Ethanolic Zingiber officinale R. extract pretreatment alleviates isoproterenol-induced oxidative myocardial necrosis in rats. Indian J Exp Biol 2006, 44, 892-897.

15. Nazam Ansari M., Ganaie M.A., Ur Rehman N., Alharthy K.M., Khan T.H., Imam F., Ansari M.A., Al-Harbi N.O., Jan B.L., Sheikh I.A., Hamad A.M.: Protective role of Roflumilast against cadmium-induced cardiotoxicity through inhibition of oxidative

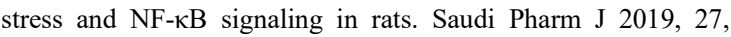
673-681, doi: 10.1016/j.jsps.2019.04.002.

16. Oeckinghaus A., Ghosh S.: The NF-kappaB family of transcription factors and its regulation. Cold Spring Harb Perspect Biol 2009, 1, a000034, doi: 10.1101/cshperspect.a000034.

17. Oladipo O.O., Ayo J.O., Ambali S.F., Mohammed B., Aluwong T.: Dyslipdemia induced by chronic low dose co-exposure to lead, cadmium and manganese in rats: the role of oxidative stress. Environ Toxicol Pharmacol 2017, 53, 199-205, doi: 10.1016/j.etap.2017.06.017

18. Refaie M.M.M., El-Hussieny M., Bayoumi A.M.A., Shehata S.: Mechanisms mediating the cardioprotective effect of carvedilol in cadmium induced cardiotoxicity. Role of eNOS and HO1/Nrf2 pathway. Environ Toxicol Pharmacol 2019, 70, 103198, doi: 10.1016/j.etap.2019.103198.

19. Romão P.V.M., Palozi R.A.C., Guarnier L.P., Silva A.O., Lorençone B.R., Nocchi S.R., Sari Moura C.C., Lourenço E.L.B., Silva D.B., Gasparotto Junior A.: Cardioprotective effects of Plinia cauliflora (Mart.) Kausel in a rabbit model of doxorubicininduced heart failure. J Ethnopharmacol 2019 242, 112042, doi: 10.1016/j.jep.2019.112042.

20. Sarmiento-Ortega V.E., Brambila E., Flores-Hernández J.Á., Díaz A., Peña-Rosas U., Moroni-González D., Aburto-Luna V., Treviño S.: The NOAEL Metformin dose is ineffective against metabolic disruption induced by chronic cadmium exposure in Wistar rats. Toxics 2018, 6, 55, doi: 10.3390/toxics6030055.

21. Schneider C. A., Rasband W. S., Eliceiri K. W.: NIH Image to ImageJ: 25 years of image analysis. Nature Methods 2012, 9, 671-675, doi: 10.1038/nmeth.2089.

22. Sugita M., Izuno T., Tatemichi M., Otahara Y.: Cadmium absorption from smoking cigarettes: Calculation using recent findings from Japan. Environ Health Prev Med 2001, 6, 154-159, doi: 10.1007/BF02897963.

23. Valdecantos M.P., Pérez-Matute P., Martínez J.A.: Obesity and oxidative stress: role of antioxidant supplementation (in Spanish). Rev Invest Clin 2009, 61, 127-139.

24. Yuan G., Dai S., Yin Z., Lu H., Jia R., Xu J., Song X., Li L., Shu Y., Zhao X., Chen Z., Fan Q., Liang X., He C., Yin L., Lv C., Lei Q., Wang L., Mi Y., Yu X., Zhang M.: Sub-chronic lead and cadmium co-induce apoptosis protein expression in liver and kidney of rats. Int J Clin Exp Pathol 2014, 7, 2905-2914.

25. Zhang C., He S., Li Y., Li F., Liu Z., Liu J., Gong J.: Bisoprolol protects myocardium cells against ischemia/reperfusion injury by attenuating unfolded protein response in rats. Sci Rep 2017, 7, 11859, doi: 10.1038/s41598-017-12366-8. 